\title{
Equipoise, placebo in clinical trials and Brazilian Code of Medical Ethics
}

\author{
Francisco José Roma Paumgartten * *
}

\section{INTRODUCTION}

Physicians must act to their patients' best interests and thus they are always expected to offer them what they believe is the best treatment for their diseases. Owing to this moral commitment, when physicians are researchers conducting randomized controlled trials (RCTs), a dilemma may arise if they suspect that one trial arm is more effective and/or safer than the other(s). If this is the case, professional ethics dictates that they should recommend their patients not to enroll in the trial and to take the therapy the physician thinks is the best for the patient's illness. As a scientist, however, they know that by doing so the insight on the clinical superiority of one trial arm (treatment) over the other(s) may remain unproven. Moreover, the physician is also aware that clinical studies, if scientifically valid and soundly designed, are beneficial for the society. For instance, the practice of evidence-based medicine requires good-quality empiric evidence as that provided by RCTs.

This ethical issue was made explicit by Shaw and Chalmers ${ }^{1}$ when addressing the ethics of cooperative clinical trials. According to them, a clinical research must not be initiated if the physician-researcher "knows or has a good reason to believe that one arm of the trial is even slightly better than the other." It was Charles Fried" in "Medical Experimentation: Personal Integrity and Social Policy," however, who first used the term "equipoise" (an equilibrium state or situation in which things are perfectly balanced) for an ethical principle according to which the physician/researcher must be in a state of genuine uncertainty about the relative efficacy (and/or safety) of the therapeutic alternatives being tested to render an ethically acceptable RCT. Some doctors embraced the equipoise concept, whereas others, including Freedman ${ }^{3}$, claimed that it was flawed and unworkable, and what is worse, its fragility would render many good-quality and relevant RCTs unethical. To tackle this issue, Freedman ${ }^{3}$ proposed to replace the notion of equipoise by that of clinical equipoise, or a situation in which there would be "no consensus among the expert clinical community about the comparative merits of the alternatives to be tested," or in other words, there would exist a collective professional uncertainty about treatment alternatives. Nonetheless, some physicians and researchers argue that Freedman's reformulation of equipoise concept in reality did not overcome a major objection to this principle, namely, that it is ambiguous and that, if strictly interpreted, it would also render unethical too many RCTs. So far, the controversy on whether equipoise - or clinical equipoise - is a prerequisite to make a RCT ethical has remained unresolved. Many clinicians and researchers endorse the point of view that equipoise principle, even if it eventually requires amendments, is an important ethical standard for RCTs whereas others maintain that it is inherently flawed and must be abandoned ${ }^{6-12}$.

\section{ETHICAL ISSUES ON THE USE OF PLACEBO IN RANDOMIZED CONTROLLED TRIALS}

Another debatable issue regarding the ethics of RCTs is the use of a placebo-controlled arm when there is an effective treatment for the disease or condition being investigated. Whenever we assume that there are effective treatments, the use of a placebo-controlled arm in clinical trials clashes with doctors' moral commitment to their patients, even if physicians are genuinely uncertain whether the particular treatment under investigation would be in fact superior to placebo. In principle, therefore, to use or not to use a placebo when it seems to be scientifically justified apparently opposes science to ethics. One should have in mind, however, that, according to the Hippocratic oath and medical codes of ethics, such as the World Medical Association's (WMA) Declaration of Helsinki (DoH), physicians are bound

'Oswaldo Cruz Foundation, National School of Public Health, Rio de Janeiro (RJ), Brazil.

*Corresponding author: francpaum@hotmail.com

Conflicts of interest: the authors declare there are no conflicts of interest. Funding: none.

Received on October 25, 2020. Accepted on December 04, 2020. 
Table 1. Updates of the statement on the use of placebo in clinical trials in successive revisions of the Declaration of Helsinki by the World Medical Association (WMA) between 1964 and 2013.

\begin{tabular}{|c|c|}
\hline $\begin{array}{l}\text { Declaration of } \\
\text { Helsinki (year) }\end{array}$ & Statement \\
\hline $\begin{array}{l}\text { Original version of } \\
\text { DOH (Helsinki, 1964) }\end{array}$ & $\begin{array}{l}\text { Use of placebo is not directly addressed. Statement II. } 2 \text { says: "The doctor can combine } \\
\text { clinical research with professional care, the objective being the acquisition of new } \\
\text { medical knowledge, only to the extent that clinical research is justified by its therapeutic } \\
\text { value for the patient." }\end{array}$ \\
\hline $\begin{array}{l}\text { 1st revision of DOH } \\
\text { (Tokyo, 1975) }\end{array}$ & $\begin{array}{l}\text { Use of placebo-indirectly_forbidden if there is proven treatment: Statement II.3 says: "In any } \\
\text { medical study, every patient—including those of a control group, if any—should be assured of } \\
\text { the best proven diagnostic and therapeutic method." }\end{array}$ \\
\hline $\begin{array}{l}\text { 2nd revision of DOH } \\
\text { (Venice, 1983) }\end{array}$ & Previous statement wording unaltered. \\
\hline $\begin{array}{l}\text { 3rd revision of DOH } \\
\text { (Hong Kong, 1989) }\end{array}$ & Previous statement wording unaltered. \\
\hline $\begin{array}{l}\text { 4th revision of DOH } \\
\text { (Somerset-West, } \\
\text { South Africa, 1996) }\end{array}$ & $\begin{array}{l}\text { Statement II. } 3 \text { explicitly forbade the use of placebo whenever there is a proven effective } \\
\text { therapy. "In any medical study, every patient-including those of a control group, if any- } \\
\text { should be assured of the best proven diagnostic and therapeutic method. This does not } \\
\text { exclude the use of inert placebo in studies where no proven diagnostic or therapeutic } \\
\text { method exists." }\end{array}$ \\
\hline $\begin{array}{l}\text { 5th revision of DOH } \\
\text { (Edinburgh, 2000) }\end{array}$ & $\begin{array}{l}\text { Statement wording slightly modified, again it (C 29) explicitly forbade the use of placebo if } \\
\text { there is effective therapy: The benefits, risks, burdens, and effectiveness of a new method } \\
\text { should be tested against those of the best current prophylactic, diagnostic, and therapeutic } \\
\text { methods. This does not exclude the use of placebo, or no treatment, in studies where no } \\
\text { proven prophylactic, diagnostic, or therapeutic method exists. }\end{array}$ \\
\hline $\begin{array}{l}\text { 6th revision of } \mathrm{DOH} \\
\text { (Tokyo, 2004) }\end{array}$ & Previous statement wording unaltered. \\
\hline $\begin{array}{l}\text { 7th revision of DOH } \\
\text { (Seoul, 2008) }\end{array}$ & $\begin{array}{l}\text { The statement was modified to allow the use of placebo, even when there is effective } \\
\text { treatment, in some particular cases: } \\
\text { - Use of Placebo. } 33 \text {. The benefits, risks, burdens, and effectiveness of a new intervention } \\
\text { must be tested against those of the best current proven intervention, except in the following } \\
\text { circumstances: } \\
\text { - The use https://www.wma.net/policies-post/wma-declaration-of-helsinki-ethical-principles- } \\
\text { for-medical-research-involving-human-subjects/of placebo, or no treatment, is acceptable in } \\
\text { studies where no current proven intervention exists or } \\
\text { - Where for compelling and scientifically sound methodological reasons the use of placebo is } \\
\text { necessary to determine the efficacy or safety of an intervention and the patients who receive } \\
\text { placebo or no treatment will not be subject to any risk of serious or irreversible harm. } \\
\text { - Extreme care must be taken to avoid abuse of this option\# }\end{array}$ \\
\hline $\begin{array}{l}\text { Current version of } \\
\text { DOH (Fortaleza, 2013) }\end{array}$ & $\begin{array}{l}\text { Use of Placebo (statement 33) remains allowed under certain circumstances. Previous } \\
\text { statement wording unaltered. }\end{array}$ \\
\hline
\end{tabular}

"Portuguese translation (by AMB-Brazilian Medical Association): "Uso de Placebo. Os benefícios, riscos, ônus e efetividade de uma nova intervenção devem ser testados contra aqueles da(s) melhor(es) intervenção(ões) comprovada(s), exceto nas seguintes circunstâncias: Quando não existe intervenção comprovada, o uso de placebo, ou não intervenção, é aceitável; ou Quando por razões metodológicas e cientificamente sólidas, o uso de qualquer intervenção menos efetiva que a melhor comprovada, o uso de placebo, ou não intervenção, é necessário para determinar a eficácia ou segurança de uma intervenção e os pacientes que recebem qualquer intervenção menos efetiva que a melhor comprovada,placebo, ou não intervenção, não estarão sujeitos a riscos adicionais de danos graves ou irreversíveis como resultado de não receber a melhor intervenção comprovada. Extremo cuidado deve ser tomado para evitar abuso desta opção." Current and previous DoHs and translation into Portuguese are available on WMA website: https://www.wma.net/policies-post/wma-declaration-of-helsinki-ethicalprinciples-for-medical-research-involving-human-subjects/ 


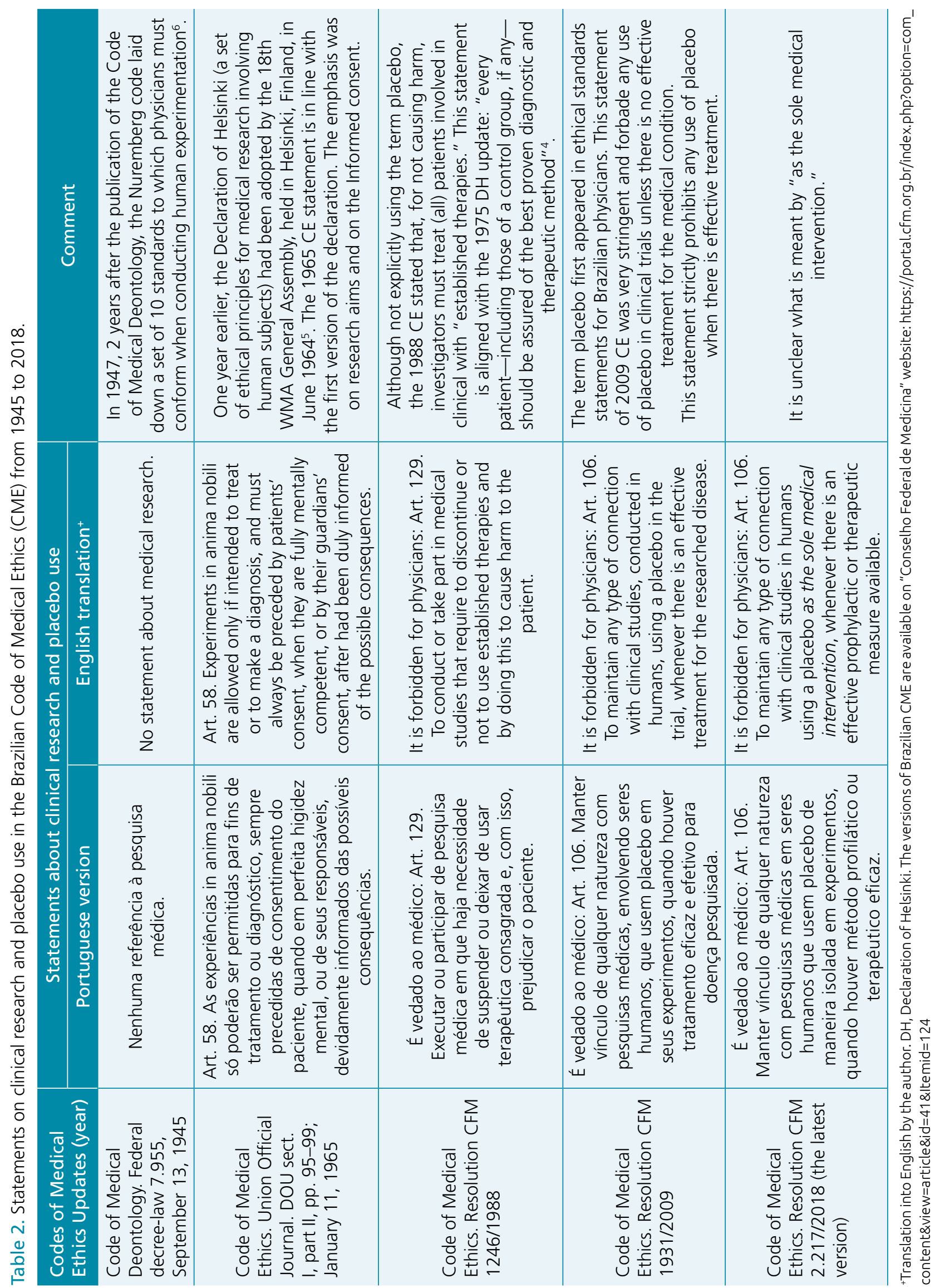


to their solemn oath ("The health of my patient will be my first consideration") and so their acts as healers must always take precedence over their duties as scientists ${ }^{13}$.

Whether placebo use in RCTs is scientifically justifiable and ethical, if there are approved treatments, has been debated over the last 6 decades or $\mathrm{so}^{14}$. At the time when WMA issued the first version of DoH, Bradford Hill, a pioneer in the use of randomization in clinical trials, expressed his view that "If there is such an orthodox treatment the question hardly arises, for the doctor will wish to know whether a new treatment is more, or less, effective than the old, not that it is more effective than nothing" ${ }^{14}$. Hill's opinion is consistent with WMA's ethical guidance (DoHs from 1975 to 2008) stating that: "every patient including those of a control group, if any - should be assured of the best proven diagnostic and therapeutic method" (Table 1). In 1996s, DoH revision, a sentence ("This does not exclude the use of inert placebo in studies where no proven diagnostic or therapeutic method exists") was added to emphasize that placebo use is forbidden whenever there are proven effective treatments. This emphasis was found necessary in the aftermath of a questionable placebo-controlled RCT conducted to investigate whether a specific AZT regimen ("076 Regimen") would reduce mother-child HIV-1 transmission in Uganda and Thailand. In 1994, when the trial began, it was already known that AZT was effective against HIV, and thus treating HIV-infected women with placebo was considered morally outrageous. Moreover, ethical double standard for trials in developed and developing countries was considered unacceptable ${ }^{16}$.

A subsequent DoH (2008) revision tempered the ban on placebo use wherever there exist proven therapies ("where for sound methodological reasons the use of placebo is necessary ... and the patients who receive placebo or no treatment will not be subject to any risk of serious or irreversible harm"). This exception was maintained unaltered in 2013 s revision.

\section{PLACEBO ADVANTAGES OVER ACTIVE COMPARATORS}

Depending on the RCT, placebos may have advantages over proven effective comparators. Active comparators show whether efficacy and safety of test treatments (drugs) are better, noninferior (noninferiority trials), or worse than those of approved drugs whereas a placebo control indicates whether they are effective and safe in absolute terms. As commented by Hill, as far as effectiveness is concerned, comparison with standard ("orthodox") therapy is what generally matters. A different picture may arise, however, when the primary focus is safety.

Studies on the safety of rofecoxib $\left(\operatorname{Vioxx}^{\circledR}\right)$, a COX-2-selective NSAID, illustrate how comparisons with approved drugs may mislead the interpretation of findings if modes of action are distinct. A premarketing (VIGOR - Vioxx ${ }^{\circledR}$ Gastrointestinal Outcomes Research) RCT of rofecoxib versus naproxen, a nonselective COX inhibitor, suggested that it increased cardiovascular risks, a finding then attributed to heart protective effects of the active comparator. A postmarketing placebo-controlled trial (APPROVe - Adenomatous Polyp PRevention On Vioxx), however, confirmed that rofecoxib increased (twofold) risks of serious cardiovascular events, a conclusion that led to its withdrawn from the market ${ }^{17}$. Vioxx ${ }^{\oplus}$ RCTs exemplify how using active instead of inactive comparators may bias the evaluation of safety.

It is of note that lack of a placebo-control arm in RCTs may downplay effectiveness evaluation as well. Placebos are by no means "inactive" interventions. Placebo effects are useful in the management of anxiety, depression, pain, and some other illnesses or psychosomatic conditions with strong emotional components ${ }^{18}$. For instance, meta-analyses of antidepressant RCTs have brought to light not only a strong placebo response but also the statistically significant differences of response between ADs and placebos may not be clinically meaningful. The real magnitude of antidepressant and anxiolytic response to pharmacological interventions is likely to remain blunted if placebo arms are missing in RCTs. The same holds true for anti-obesity drugs ${ }^{19}$. Although there is a set of weight-loss medications in the market, anti-obesity RCTs, as a rule, use placebo controls. If active comparators instead of placebos had been used in these trials, the absolute efficacy and safety of tested new anti-obesity drugs would have remained unclear.

Although not supplying data on relative efficacy/tolerability, placebos are better than active comparators to estimate assay sensitivity and thus the study internal validity and to fully unveil its clinical relevance. Additional advantages are that inactive comparators generally require smaller sample sizes and are less costly.

\section{COUNTERBALANCING ETHICAL ARGUMENTS}

The use of placebo in clinical practice is unacceptable because by doing so, physicians consciously deceive their patients, even if, presumably, they do it for their benefit. In soundly designed RCTs, however, patients are informed about trial details, benefits, and risks and are expected to freely give their consent to participate. If participants are fully aware about the health consequences of receiving a placebo instead of the test drug, then the burden of the decision-making is transferred to them. Patients' informed consent is a prima facie obligation for RCTs and patients' right to self-determination must always take precedence. Nonetheless, full autonomy in decision-making, to 
provide the relevant information in an understandable way and check whether patients in fact understood it, is necessary to obtain a valid consent ${ }^{20}$.

The social value of the study, one of the requirements to render it ethical, and the scientific justification for using inactive comparators, must be fairly and clearly explained to obtain an informed consent. Patients (who do not have limitations to consent) must have the right to self-determination and to freely decide to take part in placebo RCTs not only because of expected individual health benefits but also for altruistic reasons. In this regard, a parallel can be drawn on placebo RCTs and the enrollment of healthy volunteers in early clinical phases of drug research and development. In the absence of foreseeable benefits to healthy volunteers or patients, an ethical consensus has been reached that individual risks have to be proportional to the social (collective) value of the clinical trial ${ }^{21-23}$. That is, even if a trial is scientifically and socially valid, the use of inactive comparator arm is unethical whenever it implies in exposing some participants to a risk of "serious or irreversible harm" that can be treated with drugs of proven effectiveness. The anticipated risks of serious harm associated with no treatment, therefore, are insurmountable obstacles to replace active with inactive (placebo) comparators in RCTs.

\section{PLACEBO IN THE BRAZILIAN CODE OF MEDICAL ETHICS}

The Code of Medical Ethics (CME) laid down in 1965 to replace the Code of Medical Deontology of 1945, for the first time established (Art. 58) the general conditions under which a medical research is ethical. A further revision of CME in 1988, although not using the term placebo, prohibited physicians (Art. 129) "to discontinue or not to use established therapies and by doing this to cause harm to the patient." This strict prohibition on "not to use established therapies" is in line with the 1975-DoH statement that all participants should be assured of the best-proven therapeutic method. The term placebo was introduced in the 2009-CME that strictly forbade its use "whenever there is an effective treatment for the researched disease." In this new CME, the prohibition to "take part in" was extended "to maintain any type of connection with." The most recent CME (2018) maintained the prohibition but replaced "placebo" with "placebo as the sole medical intervention." It is not entirely clear what is meant by "the sole medical intervention" (Are placebo combined to "standard of care" and/ or "any adjuvant therapy" allowed?), and so it opens a room for divergent interpretations by local Ethical Committees on Clinical Research. It is noteworthy that, since 2008, WMA code (DoH) contains a straightforward statement on the conditions under which placebo use could be accepted in RCTs, even if proven effective interventions exist. A Portuguese translation of $\mathrm{DoH}$ by AMB is available on WMA's website.

\section{CONCLUDING REMARKS}

Equipoise is an ethical concept that, if taken literally, would render unethical many scientifically relevant RCTs. Whether it should be adopted as originally proposed, amended, or abandoned remains an unresolved issue. Possibly because it is controversial, equipoise requirement for RCTs is not referred to in DoH nor is it mentioned in CME.

In contrast with omission regarding equipoise, placebo use in RCTs, when proven treatment exists, is explicitly or implicitly forbidden by DoH (as of 1974) and CME (as of 1988). Since 2008, DoH allowed use of placebo instead of active comparators in some particular cases, namely when it is demonstrated that it is scientifically needed and does not result in risk of serious and/or permanent harm to patients. In 2008, CME eased the ban by replacing "placebo" with "placebo as the sole medical intervention." What "sole medical intervention" exactly refers to (standard of care?) is unclear. A rewording of CME Art. 106 to make it a straightforward statement aligned with current $\mathrm{DoH}$ is strongly recommended.

\section{REFERENCES}

1. Shaw LW, Chalmers TC. Ethics in cooperative clinical trials. Ann N Y Acad Sci. 1970;169(2):487-495. https://doi. org/10.1111/j.1749-6632.1970.tb54759.x

2. Fried C. Medical experimentation: personal integrity and social policy. United Kingdom: Oxford University Press; 1974.

3. Freedman B. Equipoise and the ethics of clinical research. $\mathrm{N}$ Engl J Med. 1987;317(3):141-145. https://doi.org/10.1056/ NEJM198707163170304

4. Lilford RJ, Jackson J. Equipoise and the ethics of randomization. J R Soc Med. 1995;88(10):552-559. PMID: 8537943
5. van der Graaf R, van Delden JJ. Equipoise should be amended, not abandoned. Clin Trials. 2011;8(4):408-416. https://doi. org/10.1177/1740774511409600

6. Kurzrock R, Stewart DJ. Equipoise abandoned? Randomization and clinical trials. Ann Oncol. 2013;24(10):2471-2474. https:// doi.org/10.1093/annonc/mdt358

7. Miller FG, Brody H. A critique of clinical equipoise. Therapeutic misconception in the ethics of clinical trials. Hastings Cent Rep. 2003;33(3):19-28. PMID: 12854452

8. Miller FG, Joffe $S$. Equipoise and the dilemma of randomized clinical trials. N Engl J Med. 2011;364(5):476-480. https:// doi.org/10.1056/NEJMsb1011301 
9. Gelfand S. Clinical equipoise: actual or hypothetical disagreement? J Med Philos. 2013;38(6):590-604. https:// doi.org/10.1093/jmp/jht023

10. Hey SP, London AJ, Weijer C, Rid A, Miller F. Is the concept of clinical equipoise still relevant to research? BMJ. 2018;360:k1065. https://doi.org/10.1136/bmj.k1065

11. London AJ. Equipoise in research: integrating ethics and science in human research. JAMA. 2017;317(5):525-526. https://doi.org/10.1001/jama.2017.0016

12. Ridker PM, Ortel TL, Hochman JS. Equipoise, Trust, and the Need for Cardiologists to Randomly Assign Patients Into Anticoagulation Trials in the Time of COVID. Circulation. 2020;142(24):2296-2298. https://doi.org/10.1161/ CIRCULATIONAHA.120.052069

13. Papakostas YG, Daras MD. Placebos, placebo effect, and the response to the healing situation: the evolution of a concept. Epilepsia. 2001;42(12):1614-1625. https://doi. org/10.1046/j.1528-1157.2001.41601.x

14. Shrestha B, Dunn L. The Declaration of Helsinki on medical research involving human subjects: a review of seventh revision. J Nepal Health Res Counc. 2020;17(4):548-552. https://doi. org/10.33314/jnhrc.v17i4.1042

15. HILL AB. Medical ethics and controlled trials. Br Med J. 1963;1(5337):1043-1049. https://doi.org/10.1136/ bmj.1.5337.1043

16. Landes M. Can context justify an ethical double standard for clinical research in developing countries? Global
Health. 2005;1(1):11. https://doi.org/10.1186/17448603-1-11

17. Carné $X, C r u z N$. Ten lessons to be learned from the withdrawal of Vioxx (rofecoxib). Eur J Epidemiol. 2005;20(2):127-129. https://doi.org/10.1007/s10654-004-6856-1

18. Kirsch I. Placebo effect in the treatment of depression and anxiety. Front Psychiatry. 2019;10:407. https://doi.org/10.3389/ fpsyt.2019.00407

19. Singh AK, Singh R. Pharmacotherapy in obesity: a systematic review and meta-analysis of randomized controlled trials of antiobesity drugs. Expert Rev Clin Pharmacol. 2020;13(1):53-64. https://doi.org/10.1080/17512433.2020.1698291

20. O'Sullivan L, Crowley R, McAuliffe É, Doran P. Contributory factors to the evolution of the concept and practice of informed consent in clinical research: A narrative review. Contemp Clin Trials Commun. 2020;19:100634. https://doi.org/10.1016/j. conctc. 2020.100634

21. Habets MG, van Delden JJ, Bredenoord AL. The social value of clinical research. BMC Med Ethics. 2014;15:66. https://doi. org/10.1186/1472-6939-15-66

22. Ganguli-Mitra A, Dove ES, Laurie GT, Taylor-Alexander S. Reconfiguring social value in health research through the lens of liminality. Bioethics. 2017;31(2):87-96. https://doi. org/10.1111/bioe.12324

23. Wendler $D$, Rid A. In Defense of a social value requirement for clinical research. Bioethics. 2017;31(2):77-86. https://doi. org/10.1111/bioe. 12325 